\title{
Three-dimensional analysis of pile groups subject to torsion
}

Ahmed F. Zidan BSc, MSc, PhD

Associate Professor, Department of Civil Engineering, Faculty of

Engineering, Beni-Suef University, Beni-Suef, Egypt (corresponding author: ahmedzidan@eng.bsu.edu.eg) (Orcid:0000-0002-7433-2564)
Osman M. O. Ramadan BSc, MSc, PhD

Professor, Structural Engineering Department, Faculty of Engineering, Cairo University, Giza, Egypt; Dean, Higher Technological Institute, Tenth of Ramadan City, Egypt

A series of three-dimensional finite-element models was developed to investigate the non-linear behaviour of pile groups connected to rigid caps and subjected to torsion. Pile groups of sizes $1 \times 2,2 \times 2$ and $3 \times 3$ installed in sand were analysed to investigate group resistance as well as the variation of pile flexural and torsion deformation. Furthermore, the relative contributions of the pile cap, pile torsion resistance and pile lateral resistance to group torsion resistance were quantitatively evaluated. The influence of group size, pile spacing, pile length, cap condition and soil stiffness was thoroughly explored. Piles were assumed to behave in a linear elastic fashion, while soil was modelled by way of the non-linear hardening-soil model. The numerical results showed that the contribution of the torsion strength of individual piles to the group overall strength decreases with the increase in group size and pile spacing but increases with the increase in pile length and soil stiffness. Among these parameters, the torsion resisted by individual piles ranged from 20 to $45 \%$ of the external applied torque. Moreover, it is found that the pile cap contributes about $7 \%$ of group resistance for surface pile caps, while this contribution increases up to $53 \%$ for embedded pile caps.

\section{Notation}

$c^{\prime} \quad$ effective cohesion

$c_{\mathrm{u}} \quad$ undrained cohesion

$D_{\mathrm{r}} \quad$ relative density

d pile diameter

$E_{\mathrm{c}} \quad$ concrete modulus

$E_{\mathrm{i}} \quad$ initial modulus

$E_{50}^{\text {ref }}$ secant Young's modulus

$E_{\text {oed }}^{\text {ref }} \quad$ odometer modulus

$E_{\text {ur }}^{\text {ref }} \quad$ unloading-reloading modulus

$E_{\mathrm{S}} \quad$ soil modulus

e distance between the ground surface and the pile head

$G_{0} \quad$ soil shear modulus

$H_{\mathrm{i}} \quad$ shear force on individual piles

$L \quad$ pile length

$M_{\mathrm{t}} \quad$ total torsion on the pile group

$M_{\mathrm{ti}} \quad$ torsional moment on individual piles

$N \quad$ standard penetration test value

$n \quad$ number of pile spacings

$P_{\mathrm{i}} \quad$ normal force on individual piles

$p_{\mathrm{r}}^{\text {ref }} \quad$ reference confining pressure

$R_{\text {intf }} \quad$ interface reduction factor

$r_{\mathrm{m}} \quad$ ratio of the external applied torque to the maximum torsion capacity of the considered pile group

$r_{\mathrm{o}} \quad$ moment arm

$r_{\mathrm{p}} \quad$ ratio of the vertical load on the pile group to the ultimate vertical capacity

$S \quad$ pile spacing

$t \quad$ thickness of the pile cap

$u_{z} \quad$ displacement in the $z$-direction

$\gamma_{c} \quad$ unit weight of concrete $\begin{array}{ll}v_{\mathrm{c}} & \text { Poisson's ratio of concrete } \\ v_{\mathrm{s}} & \text { Poisson's ratio of soil } \\ \sigma_{\mathrm{v}}^{\prime} & \text { effective overburden pressure } \\ \phi^{\prime} & \text { angle of internal friction }\end{array}$

\section{Introduction}

The behaviour of pile foundations under torsion loading is a complicated phenomenon that widely affects the performance of pile-supported structures. In some typical applications, piles are primarily loaded by axial (vertical) loads due to gravity. However, in many other applications, pile foundations are subject to significant torsion that results from lateral loads produced by wind, earthquakes, ship impact, wave actions and/or other sources. When a pile group is subject to torsion, pile resistances are mobilised in various modes: torsion, axial, shear and flexure, as shown in Figure 1. The existence of torsional load affects significantly the vertical-load-carrying capacity of the pile. The induced circumferential pile-soil interface shear stress due to torsion interacts with the mobilised skin friction accompanied by the axial load. Therefore, the axial capacity decreases and the axial movement increases (Basack and Sen, 2014).

The pile-soil interaction under torsion loads has been investigated by only a few studies in recent decades. Numerical and testing models were performed to study the behaviour of single piles subjected to torsion (Arshad and O'Kelly, 2016; Basack and Nimbalkar, 2017; Bizaliele, 1992; Chen et al., 2016; Chow, 1985; Gu et al., 2014; Guo and Randolph, 1996; Hassan, 2019; Kong and Zhang, 2007, 2008, 2009; Laue and Sonntag, 1998; Li, 2017; Misra et al., 2014; Poulos, 1975; Randolph, 1981; Stoll, 1972; Stuedlein et al., 2016; Thiyyakkandi et al., 2016; 2017; Zhang and Kong, 2006). 


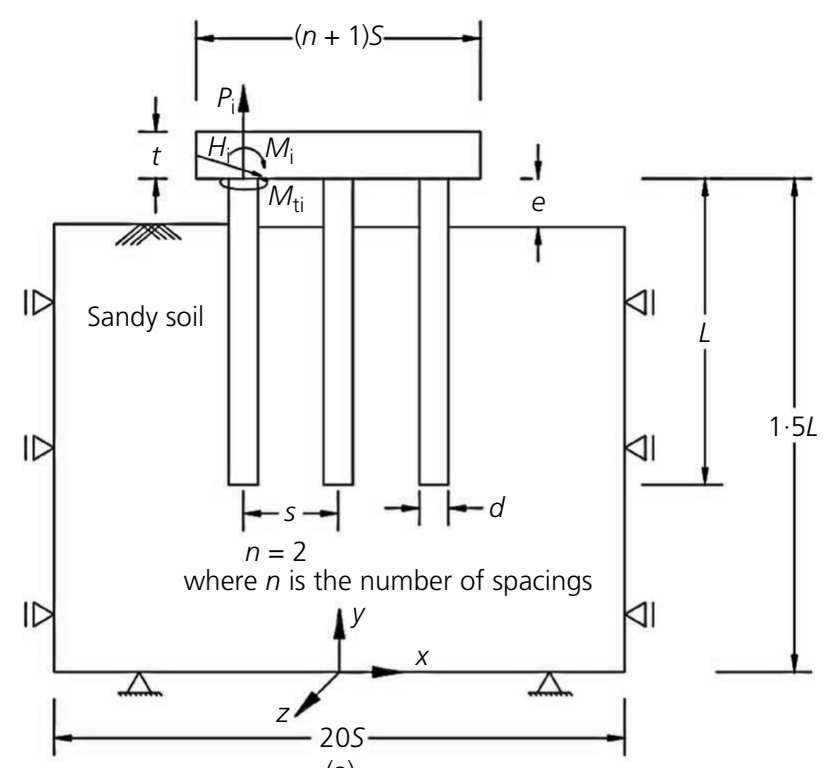

(a)

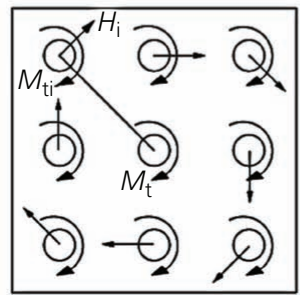

(b)

Figure 1. Sketch showing forces induced in individual piles $\left(P_{\mathrm{i}}, H_{\mathrm{i}}\right.$ and $M_{\mathrm{ti}}$ ) when the group is subject to torsion $M_{\mathrm{t}}$ : (a) elevation; (b) plan

Poulos (1975) presented charts for the torsion flexibility of a pile as a function of pile geometry and relative stiffness. He assumed a linear elastic behaviour for the pile and soil materials and accounted for the pile-soil interaction by utilising a continuum mechanics approach.

Torque-transfer models were presented by Randolph (1981). He applied the theory of elasticity to obtain the differential equation for torsion pile-soil interaction. A rather simple stress field assumption around single piles was used to develop closed-form solutions. This analysis was later extended by Guo and Randolph (1996), who included the effects of soil non-linearity and inhomogeneity and analysed the torsion response of piles in sand with a Gibson profile. Chow (1985) presented a discrete-element approach in which the pile was modelled as a series of elements and the soil was treated as a series of independent layers.

Zang and Tsang (2005) studied the response of a $2 \times 2$ bored pile group subjected to torsion using a three-dimensional (3D) finitedifference formulation. Kong and Zhang (2007) conducted a series of centrifuge model tests on torsionally loaded threediameter-spaced $1 \times 2,2 \times 2$ and $3 \times 3$ pile groups in sand. Their results indicated that the group torsion resistance increases with increasing group size and soil density. They also observed that the mobilisation of the lateral resistance of individual piles in a group is closely related to the pile location within the group due to pile-soil-pile interaction. Further, it was found that the horizontal displacement of a pile in the group is proportional to the distance from the pile to the torsion centre of the group. Thus, piles at different locations deflect dissimilarly and mobilise different shear forces and bending moments.

Kong and Zhang (2009) proposed an empirical approach to analysing the response of a free-standing pile connected to a rigid pile cap. In their approach, the lateral and torsion behaviour were modelled by $p-y$ and $\tau-\theta$ curves, where $p$ is the lateral soil reaction, $y$ is the lateral pile displacement, $\tau$ is the torsion shear stress and $\theta$ is the local twist angle of the pile. The interaction among piles was predicted from Mindlin's elastic solution, while the coupling effect of the lateral resistance of individual piles was determined using an empirical factor ' $\beta$ '. Many $p-y$ curves are presented in the literature (e.g. Kong, 2006; Reese et al., 1974; Yan and Byrne, 1992), and several $\tau-\theta$ curves for sand are also presented (Dutt and O'Neill, 1983; Hoit et al., 2001).

The present paper presents a numerical study for non-linear torsion response of pile groups with a rigid cap embedded in homogenous sandy soil. The soil is modelled by using the hardening-soil model (HSM), where the stiffness profile depends on the initial vertical and lateral stresses. Many 3D finite-element simulations are conducted using the well-known Plaxis 3D Foundation package to investigate the behaviour of pile groups subject to torsion accounting for the pile-soil-pile interaction. The influence of group size, pile length, pile spacing, embedment conditions and soil stiffness on the pile group behaviour is explored. For this purpose, the pile group behaviour is assessed in terms of $(a)$ the applied torque against the pile cap twist angle; $(b)$ distribution of individual pile deformation and internal forces with depth; and (c) contribution of the torsion strength of individual piles to the group overall strength. Therefore, the present numerical study expands the domain of the experimental studies published by Stoll (1972), Zhang and Kong (2006) and Kong and Zhang (2009).

\section{Numerical modelling}

For the numerical study, the finite-element method is employed. Plaxis 3D Foundation is used in this study as a tool for the analysis of 3D, non-linear soil-structure interaction problems (Bringkgreve and Vermeer, 1998). The parametric study designed and conducted for this work deals with the behaviour of pile caps under torsion loads. Soil-pile interaction analysis is performed in two stages. The first stage considers the soil self-weight to compute the initial stresses inside the soil mass through the procedure of at-rest pressure $K_{0}$. This stage is conducted under the drained condition prior to the construction of the pile cap. In the second stage, all movements are reset to zero before starting the pile cap installation to ensure that all displacements refer to the external loads. 
Three-dimensional analysis of pile groups

subject to torsion

Zidan and Ramadan

Table 1. Soil parameters

\begin{tabular}{|c|c|c|c|c|c|c|}
\hline Sand type & $c^{\prime}: k N / m^{2}$ & $\phi^{\prime}:^{\circ}$ & $E_{50}^{\text {ref: }} \mathrm{MPa}$ & $E_{\text {oed }}^{\text {ref }}: \mathrm{MPa}$ & $E_{\mathrm{ur}}^{\mathrm{ref}}: \mathrm{MPa}$ & $v_{\mathrm{s}}$ \\
\hline Dense sand & 1 & 40 & 35 & 35 & 105 & $0 \cdot 3$ \\
\hline Loose sand & 1 & 33 & 10 & 10 & 30 & 0.2 \\
\hline
\end{tabular}

A 15-node triangular element is adopted to simulate the soil volume and piled foundation. The behaviour of soil in the current numerical analysis is governed by HSM in order to simulate better the non-linear behaviour of soil. The description of HSM was reported in detail in the literature (Zidan, 2012; Zidan and Ramadan, 2015, 2018). Several parameters of soil are assumed to define the HSM for the two types of sand, as shown in Table 1, where $c^{\prime}$ is the effective cohesion parameter; $\phi^{\prime}$ is the angle of internal friction; $E_{50}^{\text {ref }}$ is the secant Young's modulus; $E_{\text {oed }}^{\text {ref }}$ is the odometer modulus; $E_{\mathrm{ur}}^{\mathrm{ref}}$ is the unloading-reloading modulus; $v$ is Poisson's ratio; and $R_{\text {intf }}$ is the interface reduction factor.

In addition, the values of shear strength parameters are assumed at a confining pressure of $100 \mathrm{kN} / \mathrm{m}^{2}$. In order to minimise the effect of mesh dependency, refined mesh is adopted particularly around piles and the pile cap. A thin layer of an interface element is modelled to allow relative movement between the soil and the pile to take place. Therefore, the soil properties' reduction factor, $R_{\mathrm{i}}$, is taken equal to $0 \cdot 8$, which is appropriate for friction between sand and concrete. The unit weight of the soil is assumed to be 16 and $14 \mathrm{kN} / \mathrm{m}^{3}$ for dense and loose sands, respectively.

Furthermore, the piles and pile cap are assumed to behave as linearly elastic materials with a unit weight $\left(\gamma_{\mathrm{c}}\right)$ of $25 \mathrm{kN} / \mathrm{m}^{3}$, Young's modulus $\left(E_{\mathrm{c}}\right)$ of $2 \times 10^{7} \mathrm{kN} / \mathrm{m}^{2}$ and Poisson's ratio $\left(v_{\mathrm{c}}\right)$

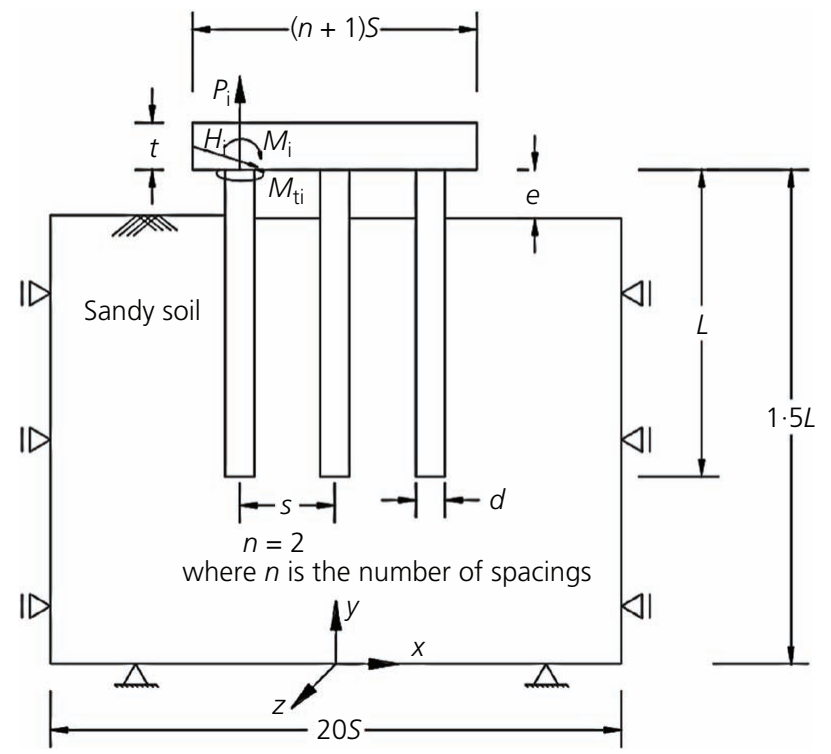

Figure 2. Vertical section of the model geometry for $n=2$. Note that $e$ is negative for embedded caps and is positive for piles with free 'unsupported' top parts of $0 \cdot 2$. The pile diameter $(d)$ is assumed to be $0.75 \mathrm{~m}$, while the pile cap thickness $(t)$ is assumed to be $1.2 \mathrm{~m}$.

For numerical application, the applied torsion load is modelled using four equal horizontal loads: each load is distributed along one of the four edges of the pile cap. Figure 2 presents a vertical section of the model geometry with the adopted 'symbolic' dimensions. Note that the vertical boundaries of the model (four faces) are restrained against horizontal translations, while its bottom boundary is restrained against both horizontal and vertical translations.

The torsion load is applied in increments until failure occurs. The variables investigated in this study include group size $(n)$, pile spacing $(S)$, pile length $(L)$, distance between the ground surface and the pile head $(e)$, soil type and vertical load carried by the pile cap $(P)$. The results are presented in terms of a few dimensionless parameters: $(L / d),(e / t)$ and so on. An example of the deformed mesh is presented in Figure 3 for the case of $L / d=15$ and $S / d=3$. This mesh includes 22477 elements and 27886 nodes. Table 2 lists the parameters of various analyses conducted in this paper.

\section{Numerical model validation}

In this verification, three reported cases are studied aimed at supporting the current numerical model. The behaviour of a single

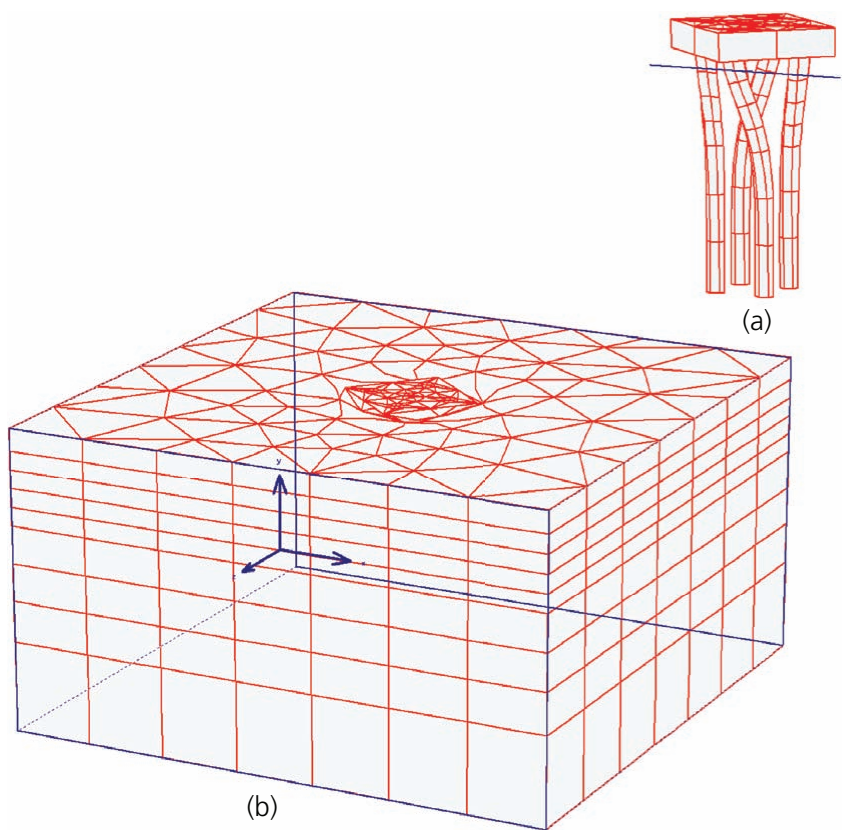

Figure 3. Example of model mesh in a deformed shape after torsion loading: (a) pile cap and piles; (b) soil elements 
Table 2. Parameters investigated in this study

\begin{tabular}{lccl} 
Group & Constant parameters & Variable parameters & Remarks \\
\hline 1 & $L / d=15$, dense soil, $S / d=3, P=0$ & Group size: $1 \times 2,2 \times 2$ and $3 \times 3$ & Influence of group size \\
2 & $2 \times 2$ pile group, $L / d=15$, dense soil, $P=0$ & $S / d=3,4,5$ & Influence of pile spacing \\
3 & $2 \times 2$ pile group, dense soil, $S / d=3, P=0$ & $L / d=10,15,20$ & Influence of pile length \\
4 & $2 \times 2$ pile group, $L / d=15, S / d=3, P=0$ & Dense and loose sands & Influence of soil stiffness \\
5 & $2 \times 2$ pile group, $L / d=15, S / d=3, P=0$ & $e=t, 0,-t$ & Influence of embedment \\
6 & $2 \times 2$ pile group, $L / d=15, S / d=3$, dense soil & $P=\Sigma p_{\mathrm{i}}=0,5,10,20$ and $30 \mathrm{MN}$ & Influence of pile vertical load
\end{tabular}

pile impeded in two-layered soil studied by Stoll (1972) is considered in the first case. In the second verification, the response of a single pile penetrated in two types of sandy soil, loose and dense sands, examined by Zhang and Kong (2006) is simulated by the current numerical model. Finally, the response of pile groups $-2 \times 2$ and $3 \times 3-$ computed by Kong and Zhang (2009) is simulated by the current numerical model.

\section{Case study 1}

Stoll (1972) examined a hollow steel single pile with a length of $11.9 \mathrm{~m}$ passed through clay soil followed by a sand one. The steel pile was filled with concrete and has an external diameter of $0.27 \mathrm{~m}$ with a wall thickness of $6.33 \mathrm{~mm}$. In the study by Stoll (1972), the soil profile included the values of a standard penetration test (SPT) $(N)$. The profile of $N$ indicates that the final resistance at the pile tip was 20 blows/foot $(6 \cdot 10$ blows $/ \mathrm{m})$. Moreover, the height of the pile above the ground surface was $1.0 \mathrm{~m}$. The applied torque and twist angle were monitored during the test. In order to simulate the same test, the soil stiffness along the pile length is based on the values of $N$ reported by Stoll (1972). In the literature, a wide range of soil modulus correlations is reported that rely on $N$. In this verification, the soil modulus $E_{\mathrm{s}}$ is computed according to the empirical equation introduced by Poulos (1994) for the axial response of a pile. In addition, these values are found to be slightly lower than that estimated with the correlation proposed by Imai and Tonouchi (1982), as referred to in the book by Kramer (1996).

1. $E_{\mathrm{s}}=14 N(\mathrm{MPa})$ for clay (Poulos, 1994)

2. $E_{\mathrm{s}}=16 \cdot 9 N^{0 \cdot 9}(\mathrm{MPa})$ for sand (Poulos, 1994)

$$
G_{0}=15600 N_{60}^{0.68}(\mathrm{kPa})
$$

3. for sand (Imai and Tonouchi, 1982)
According to Stoll (1972), an average $N$ value of 4 was assigned for the top layer, soft clay. For the sandy layer, the value of $N$ started from 4 at the top of the layer and reached 20 at the pile tip. Furthermore, the undrained shear strength parameter $\left(c_{\mathrm{u}}\right)$ was determined from the correlation $c_{\mathrm{u}}=4 \cdot 5 N$ (Stroud, 1975). The internal friction angle $(\phi)$ is computed from SPT $N$ values, as reported by Peck et al. (1967). As the test is modelled numerically through HSM, the secant modulus is assumed to be about $0 \cdot 55 E_{\mathrm{s}}$, as described in the literature. For instance, Dung (2009) studied the modulus of Baskarp sand, and he found that $E_{50}$ equals about $55 \%$ of the initial modulus $\left(E_{\mathrm{i}}\right)$ for both loose and dense sands. The hyperbolic parameters were determined by a laboratory test by Anaraki (2008) and derived numerically by Dung (2009) using the soil test facilities in Plaxis 2D. The assigned parameters for numerical simulation are shown in Table 3.

It is also worth mentioning that the interface resistance between soil and pile circumference is a crucial issue for the pile-soil interaction problem. Hence, in the current numerical analysis, the interface coefficient $\left(R_{\text {intf }}\right)$ is assumed to be 0.8 for sand and 0.5 for clay (Tomlinson, 1980; Zidan, 2019). Figure 4 shows the comparison between field test results obtained by Stoll (1972) and the current numerical model. Despite the results of numerical model underestimating the lateral torsional capacity at the majority of twist levels due to the lack of knowledge regarding soil properties, the overall trend shows a satisfactory match between the numerical model and field data.

\section{Case study 2}

Zhang and Kong (2006) conducted centrifuge tests on a single pile jacked in two types of sand, loose and dense sands, to investigate the pile torsional response. All tests were performed at $40 \mathrm{~g}$ by a four-axis robotic manipulator. In their experimental study, the relative densities of loose and dense sands were 32 and $75 \%$, respectively, with $D_{50}=0.14 \mathrm{~mm}$. In addition, the maximum and minimum dry densities for sand were 1.59 and $1.32 \mathrm{~g} / \mathrm{cm}^{3}$, respectively; hence, the corresponding void ratios

Table 3. Input soil parameters for the case studied by Stoll (1972)

\begin{tabular}{|c|c|c|c|c|c|c|}
\hline Layer & $c_{\mathrm{u}}: \mathrm{kPa}$ & $\phi^{\prime}:{ }^{\circ}$ & $E_{50}^{\mathrm{ref}}: \mathbf{k N} / \mathrm{m}^{2}$ & $E_{\text {oed }}^{\text {ref }}: \mathrm{MPa}$ & $E_{\mathrm{ur}}^{\text {ref: }} \mathrm{MPa}$ & $v_{\mathrm{s}}$ \\
\hline Top layer & 18 & 0 & 28 & 28 & 56 & 0.4 \\
\hline Second layer & 1 & 30 & $76 \cdot 9^{a}$ & $76 \cdot 9$ & 153 & $0 \cdot 3$ \\
\hline
\end{tabular}

a This value is computed at the middle of the layer where the stiffness increases with depth (16.3 MPa/m according to the soil profile) 
Three-dimensional analysis of pile groups

subject to torsion

Zidan and Ramadan

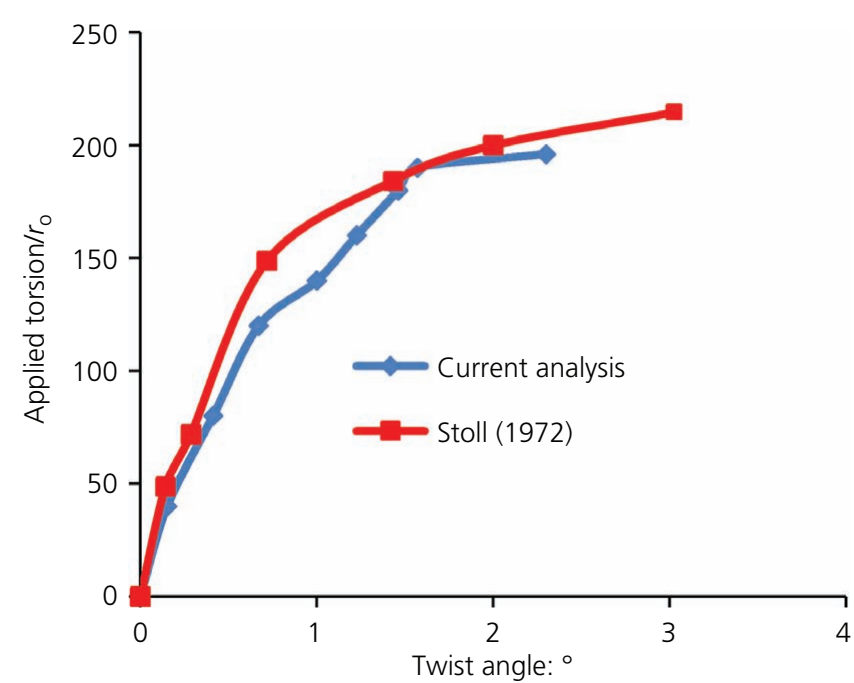

Figure 4. Torque-twist angle relationship measured by Stoll (1972) compared with the current analysis

were 0.667 and 1.008 . An aluminium tube pile with an outer diameter of $15.7 \mathrm{~mm}$ and a wall thickness of $0.9 \mathrm{~mm}$ was examined. The impeded pile length and the free height above soil were 27 and $3 \mathrm{~cm}$, respectively. Moreover, a container with inside dimensions of $0.71 \times 0.58 \times 0.38 \mathrm{~m}$ was used. The torque at the pile head and the corresponding twist angle were measured throughout the tests.

In numerical simulation, as shown in Table 4, the mechanical properties of soil are calculated according to the relative densities

Table 4. Input soil parameters for the case studied by Zhang and Kong (2006)

\begin{tabular}{|c|c|c|c|c|c|c|}
\hline Sand type & $\begin{array}{c}c_{\mathrm{u}}: \\
\mathrm{kN} / \mathrm{m}^{2}\end{array}$ & $\phi^{\prime}:{ }^{\circ}$ & $\begin{array}{l}E_{50}^{\text {ref: }} \\
\mathrm{MPa}\end{array}$ & $\begin{array}{l}E_{\text {oed }}^{\text {ref }} \text { : } \\
\text { MPa }\end{array}$ & $\begin{array}{l}E_{\mathrm{ur}}^{\mathrm{ref}} \\
\mathrm{MPa}\end{array}$ & $v_{\mathrm{s}}$ \\
\hline Loo & 1 & 29 & $32 \cdot 3$ & $32 \cdot 3$ & 65 & $0 \cdot 3$ \\
\hline Dense sand & 1 & 41 & 137 & 137 & 274 & 0.3 \\
\hline
\end{tabular}

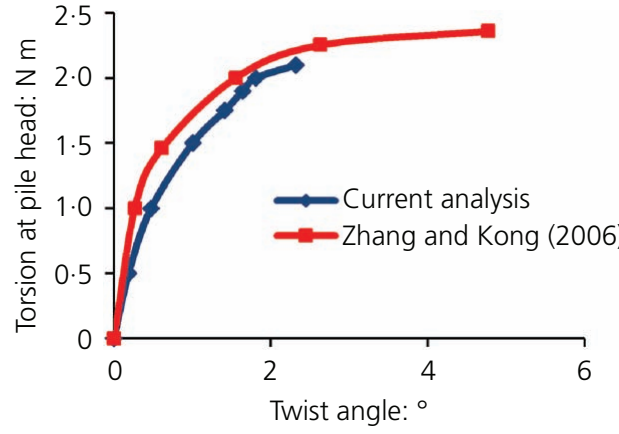

(a) of loose and dense sands, whereas the value of the SPT number $(N)$ is determined by using the correlation proposed by Cubrinovski and Ishihara (1999)

4.

$$
D_{\mathrm{r}}(\%)=\sqrt{\left[\frac{N\left(0 \cdot 23+0 \cdot 06 / D_{50}\right)^{1 \cdot 7}}{9}\left(\frac{98}{\sigma_{\mathrm{v}}^{\prime}}\right)\right]} \times 100
$$

The angle of internal friction is calculated according to Hatanaka and Uchida (1996), who presented the relationship between the friction angle and the value of $N$ where

5. $\phi=\left(20 N_{1(60)}\right)^{0.5}+20$

Figure 5 shows a comparison between graphs of reported data by Zhang and Kong (2006) and the numerical results. As observed previously in case study 1 , good agreement between numerical and experimental results can be observed.

\section{Case study 3}

Kong and Zhang (2009) proposed an empirical approach to investigating the non-linear response of a free-standing pile connected with a rigid pile cap. In their study, the proposed approach was verified with the results of the centrifuge model reported by Kong (2006) as well as Kong and Zhang (2007). These studies reported a series of centrifuge model tests on torsion-loaded single piles and pile groups in loose and dense sands. For convenience, input data and results are calculated in prototype scale with an outside pile diameter of $0.76 \mathrm{~m}$ and an embedded pile length of $10.8 \mathrm{~m}$. The flexural rigidity (EI) and torsion rigidity (GJ) of an individual pile were 220.5 and $169 \cdot 9 \mathrm{MN} \mathrm{m}^{2}$, respectively, while the Poisson's ratio of the pile was $0 \cdot 3$. The pile cap was $1.2 \mathrm{~m}$ thick and $1.2 \mathrm{~m}$ above the ground surface. Furthermore, the secant modulus $E_{50}^{\text {ref }}$ of the soil was assumed to be $7000 \mathrm{kN} / \mathrm{m}^{2}$ (Kong and Zhang, 2009) at a confining pressure of $100 \mathrm{kN} / \mathrm{m}^{2}\left(p_{\mathrm{r}}^{\text {ref }}\right)$. Other soil parameters are

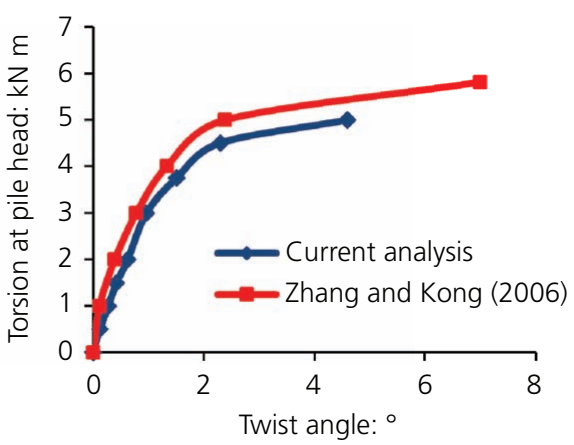

(b)

Figure 5. Applied torsion plotted against pile head rotation: (a) loose sand; (b) dense sand 
Table 5. Input parameters for cases studied by Kong and Zhang (2009)

\begin{tabular}{|lccccccc}
$\begin{array}{l}\text { Pile embedded } \\
\text { length: } \mathbf{m}\end{array}$ & $\begin{array}{c}\text { Pile free-standing } \\
\text { length: } \mathbf{m}\end{array}$ & $\begin{array}{c}\text { Pile } \\
\text { diameter: } \\
\mathbf{m}\end{array}$ & $\begin{array}{c}\text { Pile Young's } \\
\text { modulus: MPa }\end{array}$ & $\begin{array}{c}\text { Pile } \\
\text { Poisson's } \\
\text { ratio }\end{array}$ & $\begin{array}{c}\text { Soil friction } \\
\text { angle: }\end{array}$ & $\begin{array}{c}\text { Soil secant } \\
\text { modulus: } \mathbf{M P a}\end{array}$ & $\begin{array}{c}\text { Soil unit } \\
\text { weight: } \mathbf{k N} / \mathbf{m}^{3}\end{array}$ \\
\hline 10.8 & 1.2 & 0.76 & $1.35 \times 10^{4}$ & 0.3 & 33 & 7 & 13.7
\end{tabular}

reported in Table 5 and detailed in the paper by Kong and Zhang (2009). Although deviations between theoretical and test results are expected due to scale effects in centrifuge modelling, Figure 6 shows that the present numerical model reasonably agrees with both the test data and the theoretical prediction published by Kong and Zhang (2009) for the torque-twist angle curves. Having verified the suitability and accuracy of the present numerical model, it is now utilised in an extensive parametric study to investigate the influence of pile length, pile spacing, soil stiffness, embedment and so on, on the torsion response of pile groups.

\section{Numerical results}

Effect of group size

The discussion in this section is based on pile groups installed in dense sands with $L / d=15, S / d=3, P=0$ and $e=t$ (i.e. no axial loads and no embedment). Furthermore, $r_{\mathrm{m}}$ is defined as the ratio of the external applied torque to the maximum torsion capacity of the pile group. Figure 7 presents the torsion load-deformation relationships for the considered pile groups from start to failure. It is clear from Figure 7 that as the group size increases, the group torsion resistance increases, but the pile caps' torsion rotation at failure decreases. This is so because for the same pile cap rotation, peripheral piles in larger groups experience larger horizontal translations. In particular, the ratio of the maximum pile translation at the same pile cap torsion rotation for the groups of $1 \times 2,2 \times 2$ and $3 \times 3$ is equal to $d / 2: d / 2^{1 / 2}:(2 d)^{1 / 2} \approx$ $1 \cdot 0: 1 \cdot 4: 2 \cdot 8$ for the corner piles and equal to $d / 2: d / 2: d=$ $1 \cdot 0: 1 \cdot 0: 2 \cdot 0$ for the edge piles. In other words, to have the same horizontal translation at the top of corner and edge piles in groups

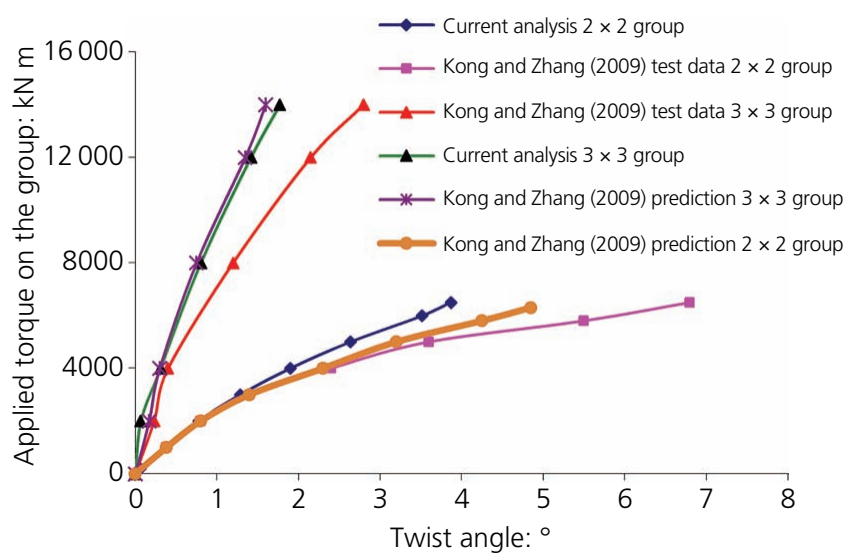

Figure 6. Torque-twist angle comparison between current analysis and the work by Kong and Zhang (2009) of $1 \times 2,2 \times 2$ and $3 \times 3$, the torsion angles should be in the ratios of $1 \cdot 00: 0 \cdot 70: 0 \cdot 35$ and $1 \cdot 00: 1 \cdot 00: 0 \cdot 50$, respectively. The ratios of maximum rotations in Figure 7 seem to be closer to those corresponding to edge piles than they are to ratios corresponding to corner piles.

The effect of group size on individual piles' torsion contribution to group torsion resistance is presented in Figure 8. This figure shows that for the small group of $1 \times 2$, the individual piles'

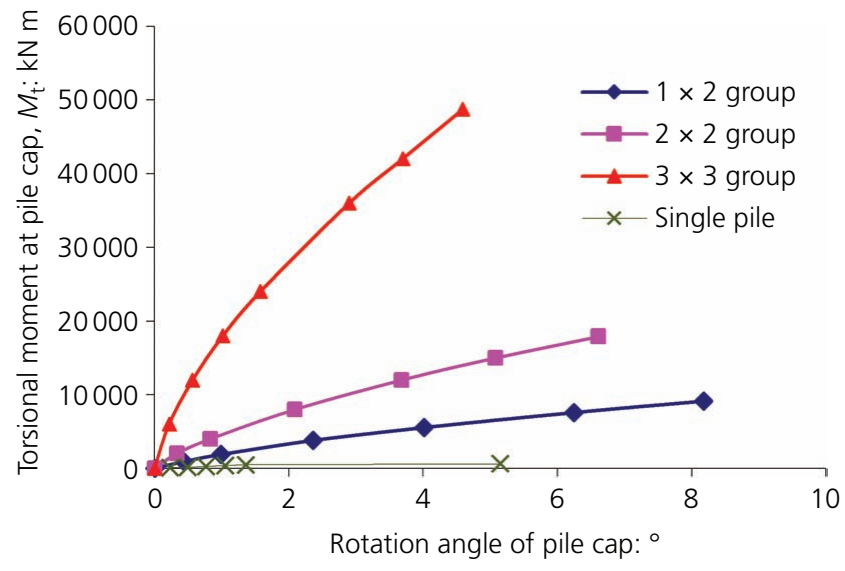

Figure 7. Effect of the group size on the torsion load-deformation relation of pile groups (dense sand, $L / d=15, S / d=3, P=0$ and $e=t)$

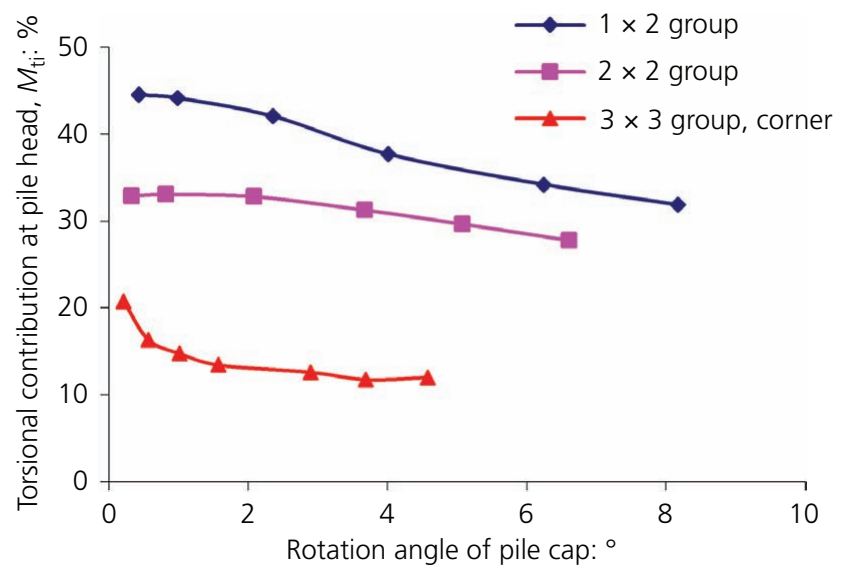

Figure 8. Effect of the group size on individual piles' torsion contribution to group torsion resistance (dense sand, $L / d=15$, $S / d=3, P=0$ and $e=t$ ) 
Three-dimensional analysis of pile groups

subject to torsion

Zidan and Ramadan torsion contribution to group torsion resistance is as high as $45 \%$ at small torsion angles but decreases with the increase in torsion angle and becomes $32 \%$ near failure. For larger group sizes of $2 \times$ 2 and $3 \times 3$, the individual piles' torsion contribution to group torsion resistance is equal to 33 and $21 \%$ and decreases to 28 and $12 \%$ near failure, respectively. Thus, the individual piles' torsion contribution to group torsion resistance decreases with the increase in group size or strain level.

To complement the investigation of the effect of pile group size on the performance of pile groups subject to torsion, Figures 9(a) and 9(b) present the over-depth variation of pile lateral deformation and pile torsion angle for the case of the $1 \times 2$ pile group. The data in each figure are presented for various load levels as determined by the parameter $r_{\mathrm{m}}$, defined as the ratio of external applied torque to the maximum torsion capacity of the considered pile group. Further, Figures 10 and 11 present data similar to that in Figure 9 for pile groups of size $2 \times 2$ and $3 \times 3$, respectively. Note that the displacement $\left(u_{z}\right)$ shown in these figures is the component of the pile top lateral displacement in the $z$-direction, which is not the total horizontal displacement for corner piles. Figures 9-11 show that the performance of piles in different groups is qualitatively similar. The soil is able to restrain the pile tip against horizontal translation at all load levels up to failure. However, as the load increases, piles develop torsion angles along their full lengths; and near failure, the torsion angle at the pile tip is as large as 65,57 and $55 \%$ of the torsion angle at the pile top for pile groups of sizes $1 \times 2,2 \times 2$ and $3 \times 3$, respectively. Thus, for pile groups subject to torsion, the soil loses control of pile torsion angles at the pile lower end at high load levels but keeps control of the pile lateral displacement at pile tips up to failure for the considered cases (dense sand, $S / d=3$ and $L / d=15)$

\section{Effect of pile spacing}

This section discusses the effect of pile spacing on pile group performance under torsion for $2 \times 2$ pile groups installed in dense sands with $L / d=15, P=0$ and $e=t$. Figure 12 presents the torsion load-deformation relationships and the individual piles'

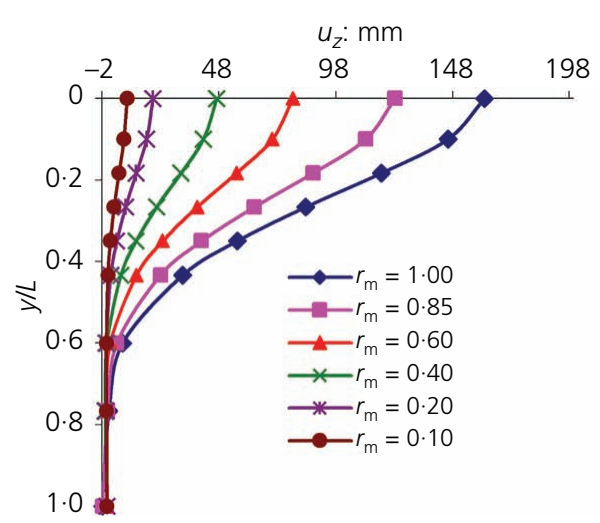

(a)

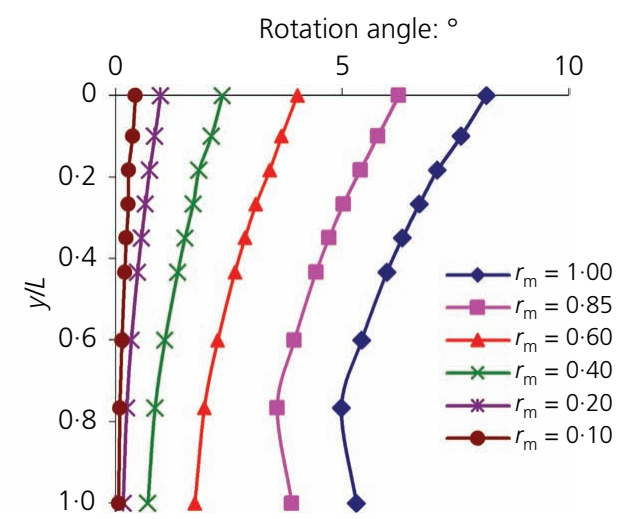

(b)

Figure 9. Pile deformation over the pile length for the $1 \times 2$ pile group (dense sand, $L / d=15, S / d=3, P=0$ and $e=t$ ): (a) lateral deformation; (b) torsion rotation

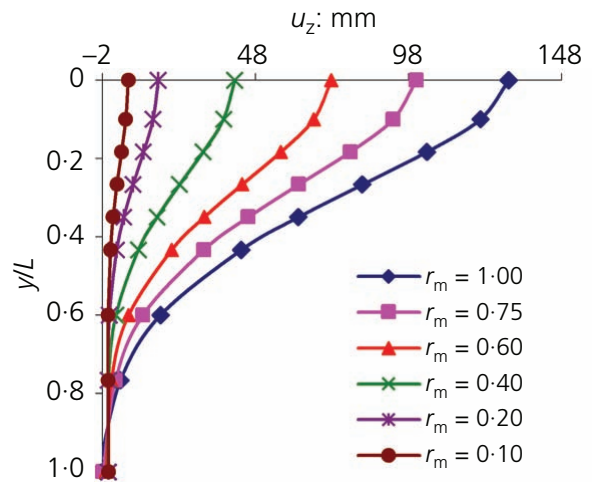

(a)

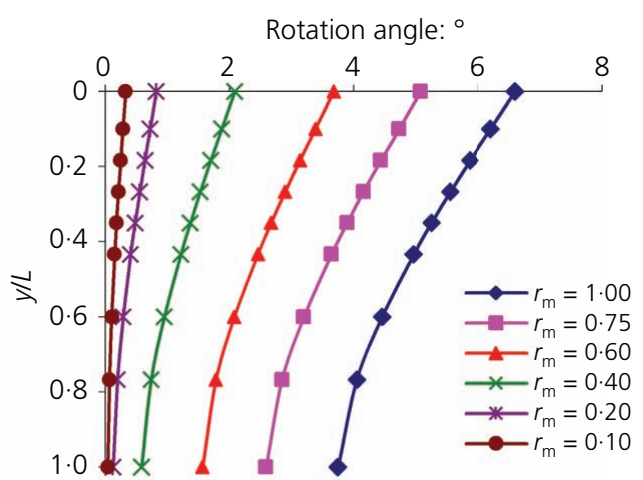

(b)

Figure 10. Pile deformation over the pile length for the $2 \times 2$ pile group (dense sand, $L / d=15, S / d=3, P=0$ and $e=t$ ): (a) lateral deformation; (b) torsion rotation 


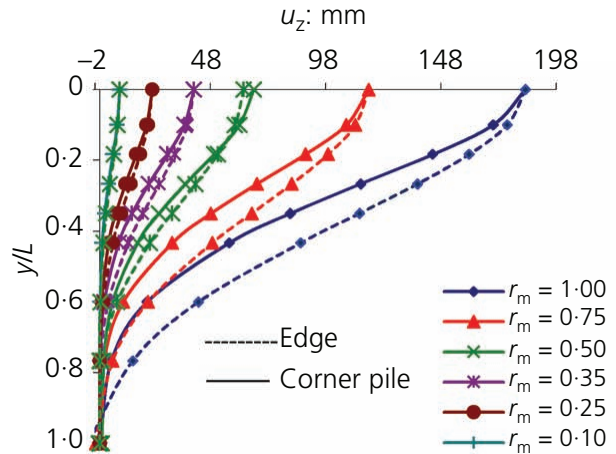

(a)

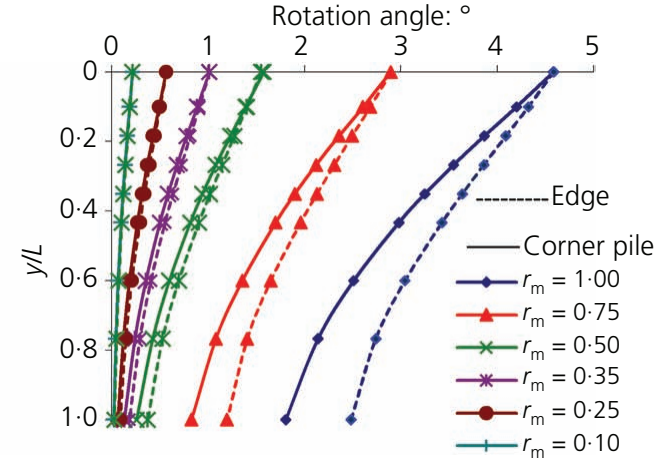

(b)

Figure 11. Pile deformation over pile length for the $3 \times 3$ pile group (dense sand, $L / d=15, S / d=3, P=0$ and $e=t$ ): (a) lateral deformation; (b) torsion rotation

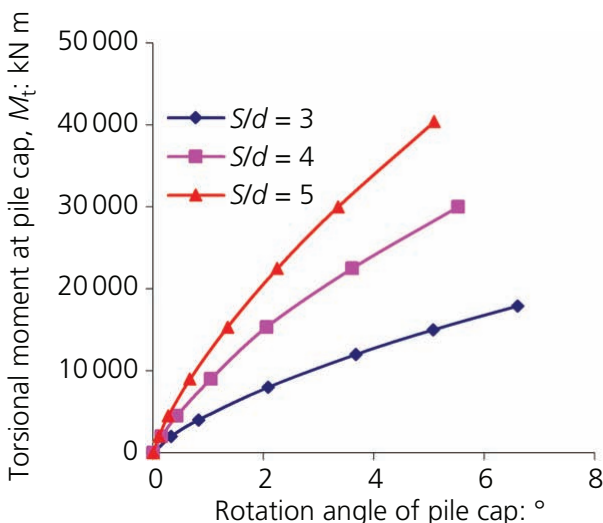

(a)

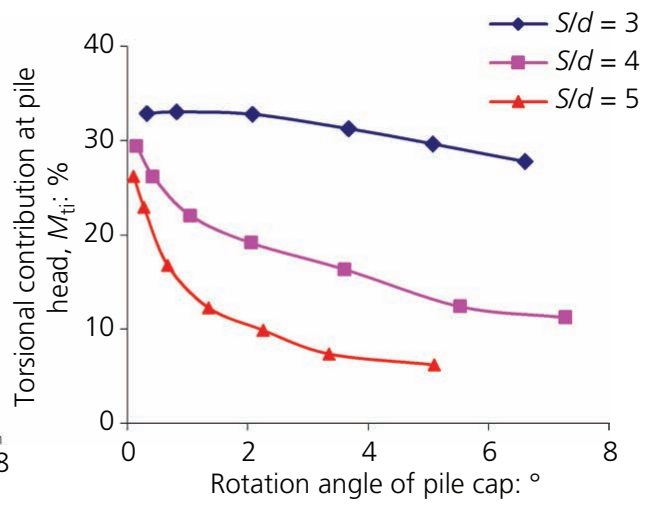

(b)

Figure 12. Effect of pile spacing on (a) group torsional resistance and (b) torsion contribution of individual piles $(2 \times 2$ pile group, L/d = 15 , dense sand, $P=0, e=t$ )

torsion contribution to the group torsion resistance of the $2 \times 2$ group for $S / d=3,4$ and 5. Figure 12(a) shows that for the same external torsion moment, as the pile spacing increases, the torsion angle greatly decreases. Furthermore, Figure 12(b) indicates that as $S / d$ increases from 3 to 4 then 5 , the individual piles' torsion contribution as a percentage of the group total resistance decreases from 28 to $12 \%$ then to $6 \%$.

Figures 13(a) and 13(b) present the over-depth variation of pile lateral deformation and pile torsion angle, respectively, for the $2 \times$ 2 pile group with $S / d=3,4$ and 5. It is clear from Figure 13 that the performance of pile groups with various spacings is qualitatively similar. However, as the pile spacing increases, the soil ability to control pile torsion angles decreases particularly at the pile lower end.

\section{Effect of pile length}

To evaluate the effect of pile length on pile group torsion performance, Figures 14(a) and 14(b) present the torsion load-deformation relationships and the individual piles' torsion contribution to group torsion resistance of the $2 \times 2$ group for $L / d=10,15$ and 20, respectively. Other parameters are kept constant in all cases: dense sands, $S / d=3, P=0$ and $e=t$. It is observed from Figure 14(a) that increasing the pile length slightly increases both pile strength and stiffness. In particular, a $100 \%$ increase in pile length (from $10 d$ to $20 d$ ) results in an $18 \%$ increase in pile group strength and a $19 \%$ decrease in the group torsion angle. Furthermore, Figure 14(b) shows that the individual piles' torsion contribution as a percentage of the group total resistance increases from $24 \%$ at $L / d=10$ to 27 and $30 \%$ as $L / d$ increases to 15 and 20, respectively. Moreover, a slight increase in group torsion stiffness with increasing pile length is manifested in Figures 15(a) and 15(b) as the power of the soil to restrain pile lateral and torsion deformation at its tip grows with the increase in $L / d$.

\section{Effect of soil type}

In order to determine the influence of soil strength on the torsional response of the pile group, the behaviour of the $2 \times 2$ pile group embedded in two different types of sand classified as loose and dense is investigated. Figures 16(a) and 16(b) show 


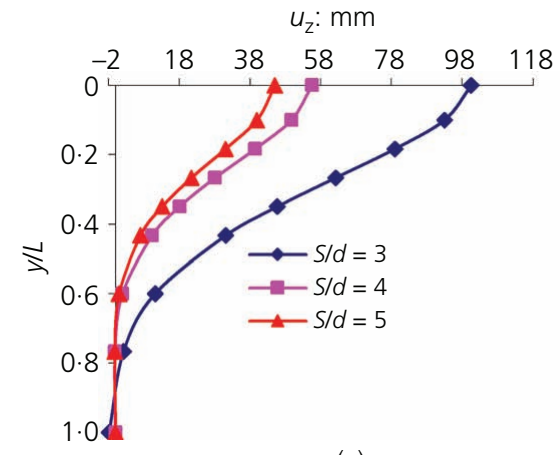

(a)

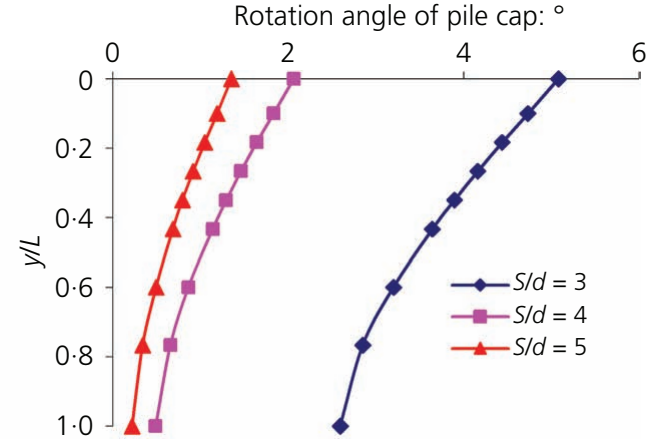

(b)

Figure 13. Effect of pile spacing on (a) pile lateral deformation and (b) rotation distribution along the pile length $(2 \times 2$ pile group, $L / d=15$, dense sand, $P=0, e=t)$

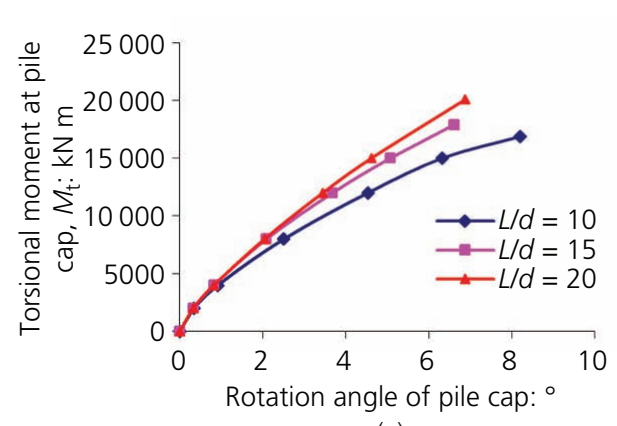

(a)

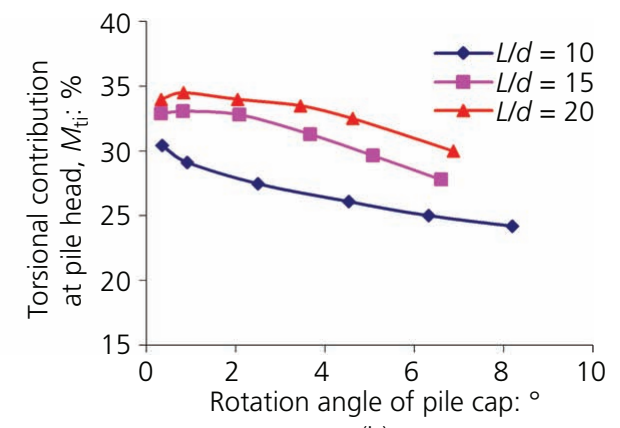

(b)

Figure 14. Effect of pile length on (a) group torsion resistance and (b) torsion contribution of individual piles $(2 \times 2$ pile group, L/d = 15 , dense sand, $P=0, e=t$ )

$u_{\mathrm{z}}: \mathrm{mm}$

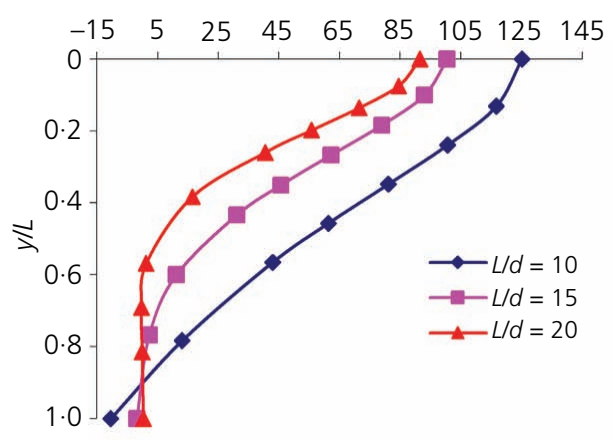

(a)

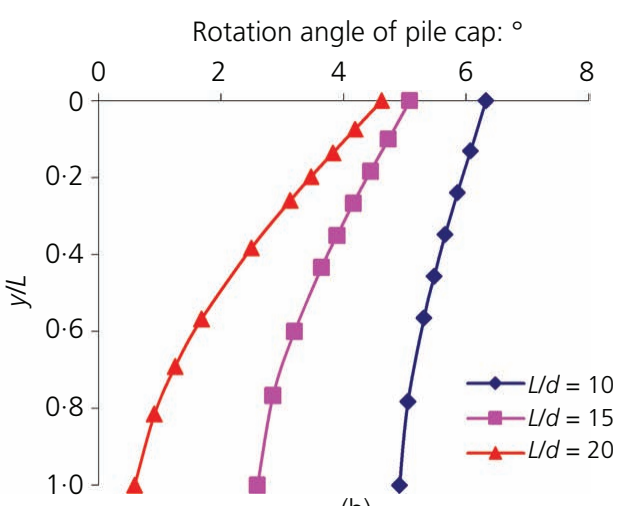

(b)

Figure 15. Effect of pile length on pile distribution of (a) lateral deformation and (b) rotation angle along pile length $(2 \times 2$ pile group, $L / d=15$, dense sand, $P=0, e=t$ )

variations of group resistance and torsional contribution of individual piles, respectively, with the rotation angle of the pile cap. A significant difference in the group response of loose and dense soils is observed from Figure 16(a). At moderate load levels, the rotation angle of the pile group in dense sand is equal to $42 \%$ of that of the group in loose sand. Moreover, near failure, the rotation angle of the group in dense sand becomes less than $32 \%$ of that of the group in loose sand.

As shown in Figure 16(b), the torsional contribution of individual piles for the group in dense sand is significantly higher than that of the group in loose sand. At low levels of applied torsion, the 


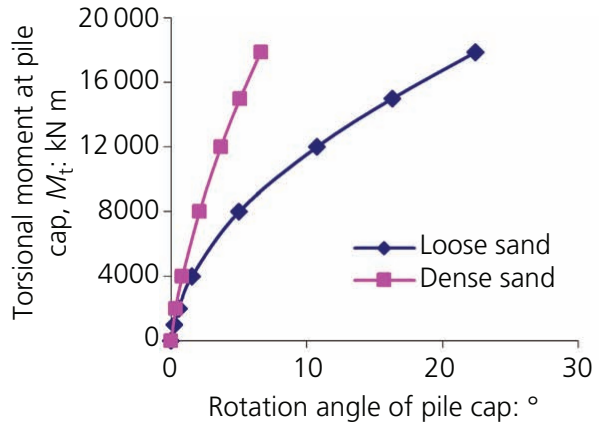

(a)

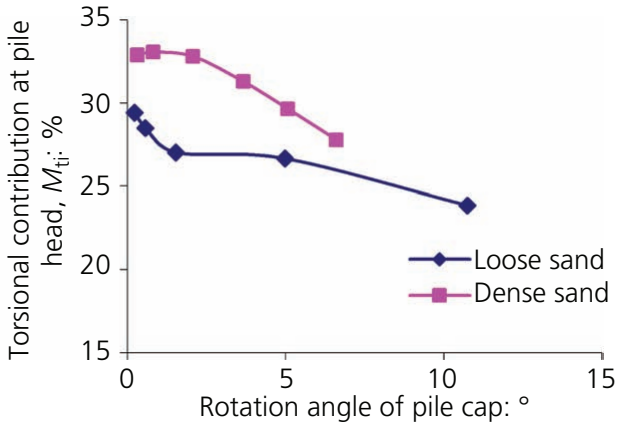

(b)

Figure 16. Effect of soil stiffness on (a) torsional resistance and (b) torsion contribution of individual piles $(2 \times 2$ pile group, $L / d=15$, dense sand, $P=0$, $e=t)$

torsional contributions of individual piles are 33 and $28 \%$ for dense and loose sands, respectively. As the applied torsion increases, these contributions decrease up to 30 and $26 \%$, respectively.

Figures 17(a) and 17(b) show the effect of soil type on variations of the pile lateral displacement $\left(u_{z}\right)$ and rotation angle with depth (y). Results in Figure 17(a) are shown for the three load levels $\left(M_{\mathrm{t}}\right.$ $=2000,8000$ and $15000 \mathrm{kN} \mathrm{m}$ ), while results in Figure 17(b) correspond to $M_{\mathrm{t}}=15000 \mathrm{kN} \mathrm{m}$. The effect of soil stiffness on pile deformation is not significant at small load levels, but it becomes remarkable at high loads. For instance, at $M_{\mathrm{t}}=15000$, the lateral displacement at the pile head for loose sand is about 3.24 times that recorded for dense sand. Finally, Figure 17(b) shows that the pile rotation for loose sand is more than three times of that for dense sand.

\section{Effect of pile cap soil interaction (pile cap embedment condition)}

In this section, the torsion behaviour of the $2 \times 2$ pile group is investigated for three pile cap embedment conditions (see Figure 2): (a) $e=t$ in which the pile cap is raised above the ground surface and piles are exposed for a distance ' $t$ ' below the pile cap, where $t$ is the thickness of the pile cap; $(b) e=0$ in which the ground surface coincides with the pile bottom surface - that is, the surface pile cap; and (c) $e=-t$ in which the ground surface coincides with the pile cap top surface - that is, the pile cap is embedded.

Figure 18(a) shows the impact of pile cap embedment condition (as determined by the coordinate $e$ ) on pile group torsional resistance and the corresponding rotation angle. The resistance of the pile group increases as embedment increases (i.e. as $e$ decreases) due to the mobilised friction between the bottom of the pile cap and soil as well as the passive resistance of surface soil in contact with pile cap side faces. In particular, the torsional capacities for the surface pile cap $(e=0)$ and the embedded cap $(e=-t)$ cases are about $1 \cdot 18$ and 1.87 times, respectively, that of the raised pile cap case $(e=t)$. Furthermore, Figure 18(b) indicates that the torsion contribution of individual piles - as a percentage of the total torsion resistance - is lowest for the raised-pile-cap case, but highest for the surface-pilecap case. Although the embedded-pile-cap case has the highest torsion resistance, the torsion contribution of individual piles as a fraction of the total resistance is larger than that of the raised pile cap but smaller than that of the surface pile cap.

From the equilibrium of forces acting on the pile cap, the summation of the torsional contribution of individual piles $\left(\Sigma m_{\mathrm{i}}\right)$,

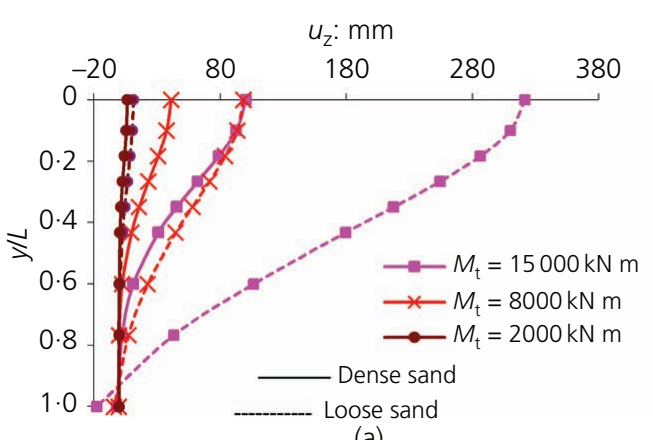

(a)

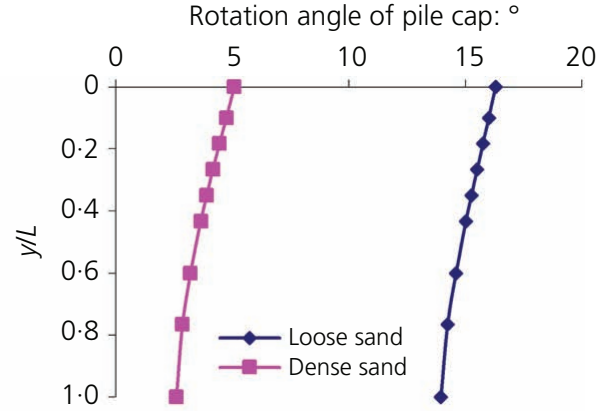

(b)

Figure 17. Effect of soil stiffness on the distribution of (a) pile lateral deformation at three load levels and (b) rotation angle at $M_{t}=$ $15000 \mathrm{kN} \mathrm{m}(2 \times 2$ pile group, $L / d=15, P=0, e=t)$ 
Geotechnical Research

Volume 7 Issue 2
Three-dimensional analysis of pile groups

subject to torsion

Zidan and Ramadan
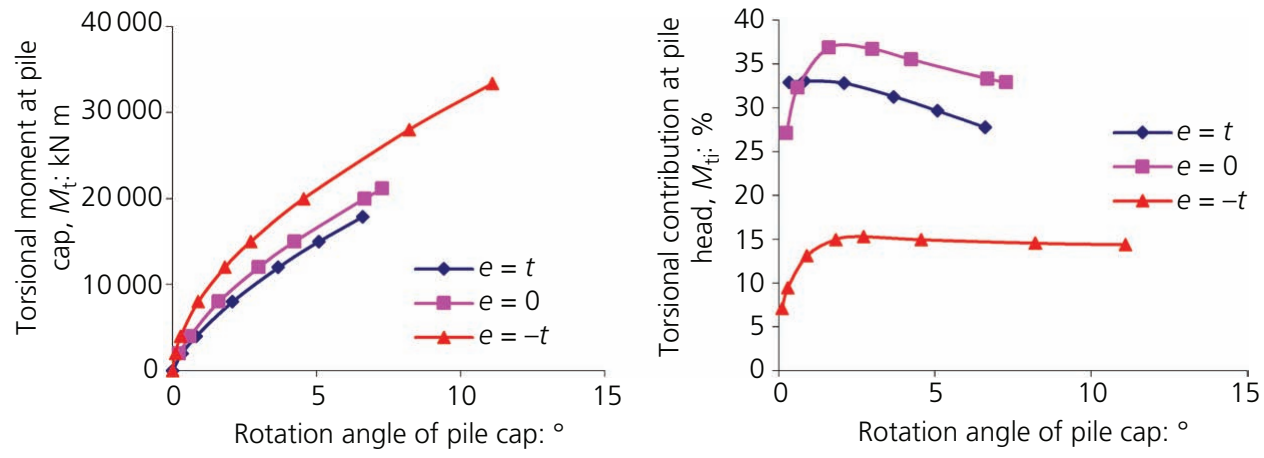

Figure 18. Effect of pile cap embedment condition on the (a) torsional resistance and (b) torsion contribution of individual piles $(2 \times 2$ pile group, $L / d=15$, dense sand, $P=0$ )

shear contribution $\left(\Sigma H_{\mathrm{i}} \times S_{\mathrm{i}}\right)$ and pile cap contribution is equal to the external, applied torsion. Figure 19 shows the relative values of these contributions at various rotation angles for the three considered pile cap embedment conditions. For the embedded cap case $(e=-t)$, the maximum contribution comes from the pile cap and is about $53 \%$ at large deformation, followed by pile shear force, then individual pile torsion contributions at 32 and 15\%, respectively. For the surface pile cap case $(e=0)$, the cap resistance relies only on bottom face friction. As a result, the contributions of pile cap, individual pile torsion and pile shear forces become about 7, 38 and 55\%, respectively. Finally, for the raised-pile-cap case $(e=t)$, the applied torsion is fully resisted by the piles alone and the contributions of individual pile torsion and pile shear forces are about 67 and 33\%, respectively.

Finally, the influence of pile cap embedment condition (distance $e$ ) on the lateral deformation and rotation angle distribution over the pile length is shown in Figure 20 at the same 'small' external torsion of $15000 \mathrm{kNm}$. As seen from Figure 20(a), the lateral deformation considerably increases in the absence of soil support to the pile cap. In addition, the effect of pile cap embedment condition is insignificant for the lower third of the pile length. At the pile head, the cap-soil interaction reduced the pile lateral displacement by 17 and $46 \%$ for the cases of surface and

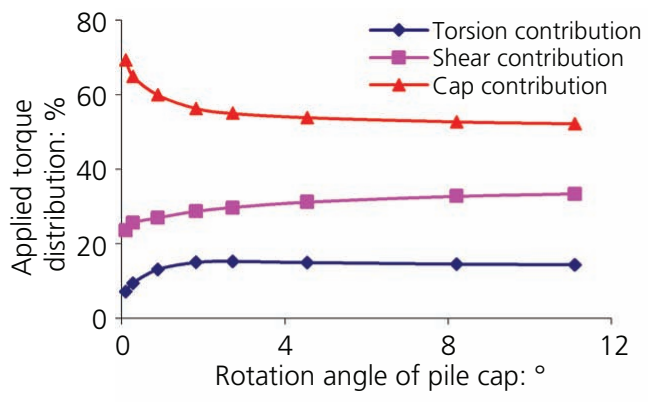

(a)

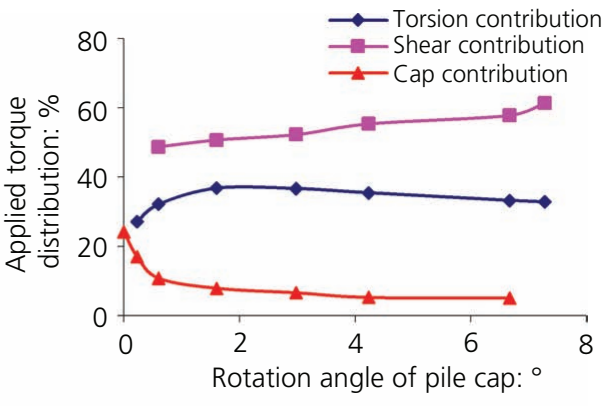

(b)

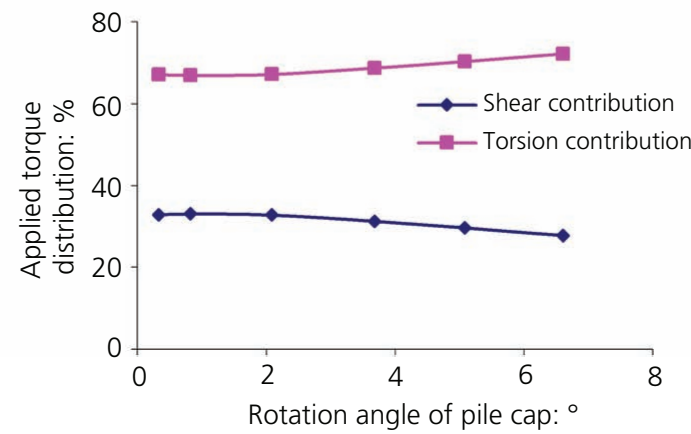

(c)

Figure 19. Torsion resistance contributions of individual piles' torsion, piles' shear forces and pile cap resistance for three embedment conditions of pile cap: (a) embedded, $e=-t$; (b), surface, $e=0$; (c) raised, $e=t(2 \times 2$ pile group, s/d = 3, $L / d=15$, dense sand, $P=0)$ 


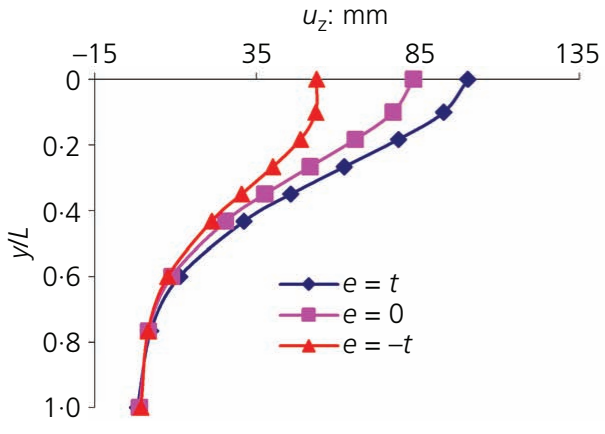

(a)

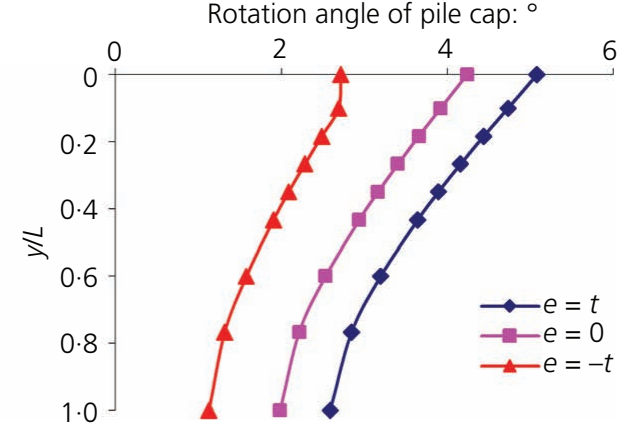

(b)

Figure 20. Effect of pile cap embedment condition on the distribution of (a) pile lateral deformation and (b) rotation angle ( $2 \times 2$ pile group, $L / d=15$, dense sand, $P=0$, small torsion moment)

embedded pile caps, respectively, compared with the case of the raised pile cap. A somewhat similar effect is observed for the torsion angle, as shown in Figure 20(b). The pile twist decreased by about 20 and $48 \%$ for surface- and embedded-cap conditions, respectively, compared with the raised-pile-cap case. Contrary to its effect on pile lateral displacement, the effect of pile cap embedment condition on the pile rotation angle continued up to pile tips.

\section{Effect of vertical load on piles}

As torsional moments on pile groups are usually accompanied by vertical loads, this section investigates the impact of vertical loads

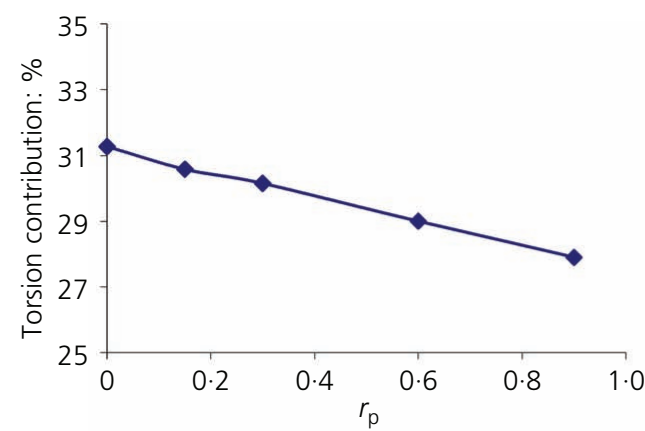

(a)

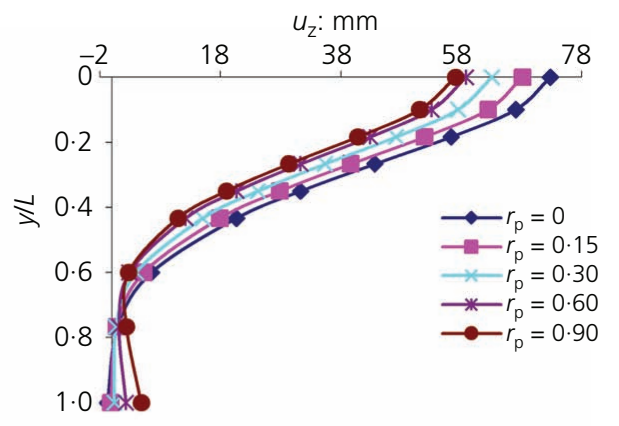

(b)

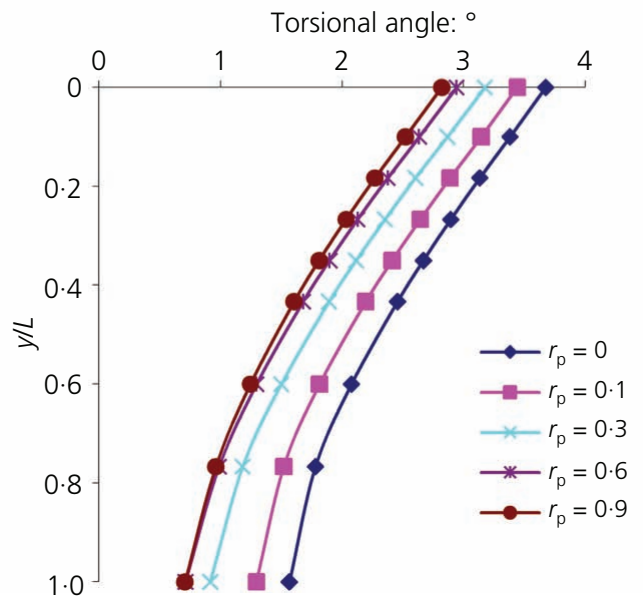

(c)

Figure 21. Effect of the vertical load level on the (a) torsion contribution of individual piles, (b) pile lateral deformation and (c) pile rotation angle $(2 \times 2$ pile group, $L / d=15$, dense sand, $e=t)$ 
on the torsion performance of pile groups. For tangible results, the vertical load is applied as a ratio of the ultimate vertical load capacity of the group in the absence of torsional moment. Moreover, a torsion moment of $12000 \mathrm{kN} \mathrm{m}$ is assumed and $r_{\mathrm{p}}$ is varied as $(0 \cdot 00,0 \cdot 15,0 \cdot 30,0 \cdot 60,0 \cdot 90)$. The assumed torsion is about equal to half the ultimate capacity of the group.

Figure 21(a) shows the variation of the torsional resistance contribution of individual piles with the ratio of the vertical load on piles $\left(r_{\mathrm{p}}\right)$. The torsional contribution of individual piles decreases almost linearly with the increase in vertical load. The effect is marginal as the torsion contribution of piles decreased from 31.5 to $27 \%$ as $r_{\mathrm{p}}$ increased from $0 \cdot 0$ to $0 \cdot 9$. However, Figure 21(b) shows that the lateral displacement of piles became more restrained as the applied vertical force increased. In addition, the lateral displacement of the pile head decreased by $21 \%$ when the vertical load ratio $\left(r_{\mathrm{p}}\right)$ increased from 0.0 to $0 \cdot 9$. Furthermore, Figure 21(c) demonstrates that values of the twist angle over the pile length also decreased as the vertical load increased.

\section{Conclusions}

A 3D finite-element model was developed to investigate the nonlinear behaviour of pile groups with rigid caps subjected to torsion. The developed model was verified by comparing its results with previously published theoretical and test results. Then, a comprehensive numerical analysis was conducted to investigate the torsional behaviour of pile groups and the relative effects of several key parameters. Based on the obtained results, the following conclusions can be drawn.

- The performance of pile groups installed in specific soil and subject to torsion generally improves with increasing pile spacing, pile length, group size or pile cap embedment.

- At a particular rotation angle, the torsional resistance for the $2 \times 2$ and $3 \times 3$ pile groups was about two and seven times, respectively, that determined for the $1 \times 2$ group.

- For pile spacing, $s$, four and five times the pile diameter, $d$, the group torsion resistance was 1.9 and 2.5 times, respectively, the group resistance corresponding to $s=3 d$.

- The individual piles' torsion contribution as a percentage of the group total resistance increases with increasing pile length from $24 \%$ at $L / d=10$ to 27 and $30 \%$ at $L / d$ of 15 and 20 , respectively.

- For 'raised' pile caps with piles protruded one pile diameter above the ground surface, the group torsion resistance contributions from individual pile torsion resistance and pile shear resistance were 67 and 33\%, respectively. When the pile cap rests at the ground surface, these contributions became 38 and $55 \%$, respectively, where the remaining $7 \%$ was resisted by pile cap friction with ground. Finally, when the pile cap is embedded to its full thickness, the relative contributions of individual pile torsion resistance, pile shear resistance and pile cap resistance became 15, 32 and 53\%, respectively. This highlights the importance of pile cap embedment condition on group response to torsion.
- The torsion stiffness of the pile group increases with the application of/increase in pile cap vertical load. In particular, for the numerical examples analysed in this paper, the lateral displacement at the pile head decreased by $21 \%$ when the vertical load increased from $0 \cdot 0$ to $90 \%$ of the group ultimate capacity.

\section{REFERENCES}

Anaraki KE (2008) Hypoplasticity Investigated Parameters Determination and Numerical Simulation. Master's thesis, Delft University of Technology, Delft, the Netherlands.

Arshad M and O'Kelly BC (2016) Analysis and design of monopile foundations for offshore wind-turbine structures. Marine Georesources \& Geotechnology 34(6): 503-525, https://doi.org/10.1080/1064119x. 2015.1033070 .

Basack S and Nimbalkar S (2017) Numerical solution of single pile subjected to torsional cyclic load. International Journal of Geomechanics 17(8): article 04017016, https://doi.org/10.1061/(ASCE)GM.1943-5622. 0000905.

Basack S and Sen S (2014) Numerical solution of single piles subjected to pure torsion. Journal of Geotechnical and Geoenvironmental Engineering 140(1): 74-90, https://doi.org/10.1061/(ASCE)GT.19435606.0000964 .

Bizaliele MM (1992) Torsional Cyclic Loading Response of a Single Pile in Sand. PhD dissertation, Ruhr-University Bochum, Bohum, Germany.

Bringkgreve RBJ and Vermeer PA (1998) PLAXIS - Finite Element Code for Soil and Rock Analyses, Version 8.2. Plaxis BV, Delft, the Netherlands.

Chen SL, Kong LG and Zhang LM (2016) Analysis of pile groups subjected to torsional loading. Computers and Geotechnics $\mathbf{7 1}$ 115-123, https://doi.org/10.1016/j.compgeo.2015.09.004.

Chow YK (1985) Torsional response of piles in non-homogeneous soil. Journal of Geotechnical and Geoenvironmental Engineering 111(7): 942-947, https://doi.org/10.1061/(ASCE)0733-9410(1985)111:7(942).

Cubrinovski M and Ishihara K (1999) Empirical correlation between SPT $N$-value and relative density for sandy soils. Soils and Foundations 39(3): 61-71, https://doi.org/10.3208/sandf.39.5 61.

Dung PH (2009) Modelling of Installation Effect of Driven Piles by Hypoplasticity. MSc thesis, Delft University of Technology, Delft, the Netherlands.

Dutt RN and O'Neill MW (1983) Torsional behavior of model piles in sand. In Geotechnical Practices in Offshore Engineering (Wright SG (ed.)). American Society of Civil Engineers, New York, NY, USA, pp. 315-334.

Gu M, Kong LG, Chen RP, Chen YM and Bian XC (2014) Response of $1 \times 2$ pile group under eccentric lateral loading. Computers and Geotechnics 57: 114-21, https://doi.org/10.1016/j.compgeo.2014.01.007.

Guo WD and Randolph MF (1996) Torsional piles in nonhomogenous media. Computers and Geotechnics 19(4): 265-287, https://doi.org/10. 1016/S0266-352X(96)00009-2.

Hasan AQ (2019) Analytical and experimental response of single pile to pure torsion. International Journal of Civil Engineering and Technology 10(3): 841-851.

Hatanaka M and Uchida A (1996) Empirical correlation between penetration resistance and internal friction angle of sandy soils. Soil and Foundations 36(4): 1-9, https://doi.org/10.3208/sandf.36.4 1.

Hoit M, Hays C, McVay M and Williams M (2001) FB-Pier Users Guide and Manual for the Analysis of Group Pile Foundation. Florida Department of Transportation and Federal Highway Administration, Tallahassee, FL, USA.

Imai T and Tonouchi K (1982) Correlation on $n$-value with s-wave velocity and shear modulus. In Penetration Testing: Proceedings of the Second European Symposium on Penetration Testing, Esopt II (Verruijt A, Beringen FL and de Leeuw EH (eds)). Balkema, Rotterdam, the Netherlands, pp. 67-72. 
Three-dimensional analysis of pile groups

subject to torsion

Zidan and Ramadan
Kong LG (2006) Behavior of Pile Groups Subjected to Torsion. PhD thesis, Hong Kong University of science and Technology, Hong Kong.

Kong LG and Zhang LM (2007) Centrifuge modeling of torsionally loaded pile groups. Journal of Geotechnical and Geoenvironmental Engineering 133(11): 1374-1384, https://doi.org/10.1061/(ASCE) 1090-0241(2007)133:11(1374).

Kong LG and Zhang LM (2008) Experimental study of interaction and coupling effects in pile groups subjected to torsion. Canadian Geotechnical Journal 45(7): 1006-1017, https://doi.org/10.1139/T08-038.

Kong LG and Zhang LM (2009) Nonlinear analysis of torsionally loaded pile groups. Soil and Foundations 49(11): 275-286, https://doi.org/10. 3208/sandf.50.341.

Kramer S (1996) Geotechnical Earthquake Engineering. Prentice Hall, Upper Saddle River, NJ, USA.

Laue J and Sonntag T (1998) Pile subjected to torsion. In Centrifuge 98: Proceedings of the International Conference Centrifuge 98, Tokyo, Japan, 23-25 September 1998 (Kimura T, Kusakabe O and Takemura J (eds)). Balkema, Rotterdam, the Netherlands, pp. 187-192.

Li O (2017) Investigation of Drilled Shafts under Axial, Lateral, and Torsional Loading. PhD thesis, School of Civil and Construction Engineering, Oregon State University, Corvallis, OR, USA.

Misra A, Saggu R, Basu D and Chakraborty T (2014) Analysis of pile subjected to torsion in multi-layered soil. International Journal for Numerical and Analytical Methods in Geomechanics 38(5): 475-492, https://doi.org/10.1002/nag.2213.

Peck RB, Hanson WE and Thornburn TH (1967) Foundation Engineering. Wiley, New York, NY, USA.

Poulos HG (1975) Torsional response of piles. Journal of Geotechnical and Geoenvironmental Engineering 101(10): 1019-1035.

Poulos HG (1994) Settlement prediction for driven piles and pile groups. In Vertical and Horizontal Deformations of Foundations and Embankments (Yeung AT and Felio GY (eds)). American Society of Civil Engineers, New York, NY, USA, Geotechnical Special Publication 40, vol. 2, pp. 1629-1649.

Randolph MF (1981) Piles subjected to torsion. Journal of Geotechnical and Geoenvironmental Engineering 107(8): 1095-1111.

Reese LC, Cox WR and Koop FD (1974) Analysis of laterally loaded pile in sand. Proceedings of the 6th Offshore Technology Conference, Houston, TX, USA, paper OTC 2080, pp. 473-483.

Stoll UW (1972) Torque shear test of cylindrical friction piles. Civil Engineering 42(4): 63-64.
Stroud MA (1975) The standard penetration test in insensitive clays and soft-rocks. Proceedings of the European Symposium on Penetration Testing, Stockholm, Sweden, vol. 2, pp. 367-375.

Stuedlein AW, Barbosa AR and Li Q (2016) Evaluation of Torsional Load Transfer for Drilled Shaft Foundations. Oregon State University, Corvallis, OR, USA, SPR 304-701.

Thiyyakkandi S, McVay M, Lai P and Herrera R (2016) Full-scale coupled torsion and lateral response of mast arm drilled shaft foundations. Canadian Geotechnical Journal 53(12): 1928-1938, https://doi.org/10. 1139/cgj-2016-0241.

Thiyyakkandi S, McVay M, Lai P and Herrera R (2017) Suitability of jetted and grouted precast pile for supporting mast arm structures. Canadian Geotechnical Journal 54(9): 1231-1244, https://doi.org/10.1139/cgj2016-0467.

Tomlinson MJ (1980) Foundation Design and Construction. Pitman, Boston, MA, USA.

Yan L and Byrne PM (1992) Lateral pile response to monotonic head loading. Canadian Geotechnical Journal 29(6): 955-970, https://doi. org/10.1139/t92-106.

Zhang LM and Tsang CYM (2005) Three-dimensional analysis of torsionally loaded large-diameter bored pile groups. In Tall Buildings: from Engineering to Sustainability (Cheung YK and Chau KW (eds)). World Scientific, Singapore, pp. 311-317.

Zhang LM and Kong LG (2006) Centrifuge modeling of torsional response of piles in sand. Canadian Geotechnical Journal 43(5): 500-515, https://doi.org/10.1139/t06-020.

Zidan AF (2019) Finite element analysis of cyclic behaviour of laterally loaded pile influenced by vertical and biaxial loading. Geomechanics and Geoengineering, https://doi.org/10.1080/17486025. 2019.1680874.

Zidan AF (2012) Numerical study of behaviour of circular footing on geogrid reinforced sand under static and dynamic loading. Geotechnical and Geological Engineering 30(2): 499-510, https://doi. org/10.1007/s10706-011-9483-0.

Zidan AF and Ramadan O (2015) Three dimensional numerical analysis of the effects of tunneling near piled structures. KSCE Journal of Civil Engineering 19(4): 917-928, https://doi.org/10.1007/s12205-0140741-6.

Zidan AF and Ramadan O (2018) A hybrid MC-HS model for 3D analysis of tunnelling under piled structures. Geomechanics and Engineering 14(5): 479-489, https://doi.org/10.12989/gae.2018.14.5.479.

\section{How can you contribute?}

To discuss this paper, please submit up to 500 words to the editor at journals@ice.org.uk. Your contribution will be forwarded to the author(s) for a reply and, if considered appropriate by the editorial board, it will be published as a discussion in a future issue of the journal. 